knowledge is rather higher than is usual for such tactical research. On this reasoning, scientists in the United Kingdom may be missing a few tricks by not doing more work on radiation effects on their own behalf.

The planners may also have missed a trick here. Developing a radiationtolerant material or device takes a very long time. In several advanced technological developments, radiation damage may often provide the limit to the usefulness of system: examples of such systems are fusion reactors and unmanned space vehicles. To obtain true effectiveness in research on radiation effects, the lead time may need to be well over ten years and start long before engineering designs take shape. A surprising amount can be gained by research which prevents device designers from pursuing the goal of radiation resistance in the wrong way. The analogy with preventive medicine is, in fact, strong and probably again extends outside the field of intricate semiconductor devices, with which the meeting in question was concerned. Because there is not, as in the United States, a well developed 'radiation effects community', the need for both underlying and short term research in this speciality may not get pressed as strongly as it should in the United Kingdom-there is no one to give the whole picture to the top level technological planners. In fact, it is notable how the 'reactor people', the 'device people'. the 'dosimetricians' and other specialists, who have a lot to gain from each other's experience, very rarely join forces either in conference or Whitehall corridor to express a common interest in two basic processes with which they are all concerned, namely displacement damage and ionisation effects. A happy exception to this is the case of the ion implantation specialists, whose techniques are useful both to reactor and device designers and whose meetings embrace both fields. This suggests that it is time for a professional body to sprout a committee which does the job of bringing together specialists.

\title{
correspondence
}

\section{Referees in print}

SIR,- - I read the recent letter by $\mathbf{H}$. Fraenkel-Conrat [Nature, March 1] concerning anonymity of scientific reviewers with some interest.

1 wonder if many readers are acquainted with the compromise system currently being used by the Journal of Geophysical Research (Space Physics), and instituted by my predecessor, W. I. Axford. Each manuscript sent out for review is accompanied by a form stating that the journal acknowledges the assistance of reviewers by naming them at the end of the paper when it finally appears in print. The reviewers are asked to indicate on the form whether they agree to being acknowledged. If they agree, the paper appears with a footnote that states: "The Editor thanks A. Smith and B. Jones for their assistance in evaluating this paper". If one of them does not agree, the statement reads: "The Editor thanks A. Smith and another referee for their assistance in evaluating this paper". If both disagree, of course, no footnote appears, but many such papers are rejected in any case.

This rather simple device has worked very well since its inception; more than $90 \%$ of our reviewers do agree to this form of acknowledgment. It not only provides some small tangible acknowledgment of the reviewer, but it also apparently reduces the incidence of irresponsible reviews that are written solely for "the joy of releasing adrenaline with anonymous impunity", as Fraenkel-Conrat describes one such effort.

To my knowledge, no other journal has yet adopted the system in spite of its demonstrated success and general acceptance among scientists in the field of space physics. It does carry with it certain corollaries that may not be acceptable to many editors-for instance, reviewers' reports must be transmitted to authors in a more or less unadulterated form, since it would hardly be fair to acknowledge a reviewer publicly for a report that had been translated and heavily doctored by the editor himself.

$$
\text { Yours faithfully, }
$$
George C. Reid

Aeronomy Laboratory,

National Oceanic and Atmospheric Administration.

Boulder, Colorado 80302

\section{Soviet scientists}

SIR,--Professor Burhop states in Nature, April 12:

"... In Western society too much concern for problems of peaceful coexistence, disarmament and the abolition of nuclear weapons is regarded as at best naive and at worst subversive. In Soviet society these things are highly regarded."

It is reassuring to think that the crowds assembled in Moscow's Red Square on May 1 and November 3 are there to protest against the parade of intercontinental missiles with nuclear warheads that we see in the news photographs. Their protest is made impressive by the fact that it is expressed as applause, which makes it more orderly.

Professor Burhop also says that Soviet scientists who wish to emigrate to Israel bear a resemblance to Oswald Mosley in 1939. This lacks verisimilitude. The British Fascisti (the BBF of
Aldous Huxley's Point Counterpoint) did not try to leave, even though many people wished they would.

Yours faithfully, Thomas H. JUKES

University of California,

Berkeley, California 94720

\section{Lead in petrol}

SIR,-In the second paragraph of the article "Lead in the Environment" (Nature, April 5, 1974). the writer states that in 1972 about 90,000 tonnes of lead were added to petrol in the United Kingdom alone. No reference is made to the source of this information but you may wish to correct the figure quoted which is grossly in error.

The Associated Octel Co. Ltd is the sole manufacturer and supplier of lead anti-knock compounds in the United Kingdom. The total production of lead alkyl compounds in 1972 was 101,000 tonnes, 27,600 tonnes of which were supplied to refiners in the United Kingdom and Eire, the remainder being exported worldwide. Since the lead metal content of anti-knock compound is approximately $40 \% \mathrm{w} / \mathrm{w}$, the total weight of lead supplied to refiners in the United Kingdom and Eire was therefore around 11,000 tonnes in 1972 . Yours faithfully,

The Associated Octel Co. Ltd,

$$
\text { R. G. AICKIN }
$$

London W1X 6DT

Our figure for United Kingdom lead additives in petrol should have been 9,000 tonnes. Its appearance as 90,000 tonnes was a printing errorEditor. 